\title{
Clinical characteristics of cardiovascular patients with extremely low levels of high- density lipoprotein cholesterol
}

\author{
Lufan Sun", Lian Duan and Dalin Jia
}

\begin{abstract}
Background: Extremely low levels of high-density lipoprotein cholesterol (HDL-C) are related to high cardiovascular mortality. The underlying mechanism is not well known. This research aims to study the clinical characteristics of cardiovascular patients with extremely low levels of HDL-C.

Methods: All cardiovascular patients in a single Chinese cardiology center that were admitted from January to December 2019 were reviewed. The clinical characteristics of those with $\mathrm{HDL}-\mathrm{C}<20 \mathrm{mg} / \mathrm{dL}$ were investigated.

Results: A total of 20,655 individuals were enrolled. Of these, $52.17 \%$ were males, and the average age was $58.20 \pm$ 12.98 years old. The prevalence of HDL-C $<20 \mathrm{mg} / \mathrm{dL}$ was $0.47 \%$ for all patients $(\mathrm{N}=98)$ and $1.05 \%$ for inpatients. Of those with $\mathrm{HDL}-\mathrm{C}<20 \mathrm{mg} / \mathrm{dL}$, $88.8 \%$ were inpatients, and $77.6 \%$ were males. Their average age was $60.7 \pm 15.1$ years. Compared with matched patients with normal HDL-C, systemic inflammation ( $\mathrm{OR}=5.556,95 \% \mathrm{Cl} 2.798-11.030)$, hypoalbuminemia $(\mathrm{OR}=5.714,95 \% \mathrm{Cl} 2.702-12.085)$, hyperuricemia (OR=5.156,95\% Cl 2.560-10.386), low T3 syndrome $(\mathrm{OR}=4.278,95 \% \mathrm{Cl} 1.627-11.245)$, anemia $(\mathrm{OR}=3.577,95 \% \mathrm{Cl} 1.680-7.617)$, diabetes $(\mathrm{OR}=3.534,95 \% \mathrm{Cl} 1.693-7.376)$ and hypertriglyceridemia $(\mathrm{OR}=2.493,95 \% \mathrm{Cl} 1.264-4.918)$ were identified as adverse concomitant factors of extremely low HDL-C. HDL-C levels were inversely correlated with the total risk scores in patients with $\mathrm{HDL}-\mathrm{C}<20 \mathrm{mg} / \mathrm{dL}(r=-0.381, P<$ $0.001)$ and more significantly correlated in patients with $\mathrm{HDL}-\mathrm{C}<15 \mathrm{mg} / \mathrm{dL}(r=-0.511, P=0.004)$.

Conclusions: Extremely low levels of HDL-C tend to occur more frequently in males, older individuals and inpatients. For cardiovascular patients, extremely low levels of HDL-C are usually due to the presence of multiple adverse factors with relatively severe conditions. This could explain the high cardiovascular mortality of individuals with extremely low levels of HDL-C.
\end{abstract}

Keywords: High-density lipoprotein cholesterol, Extreme, Low, Inflammation, Adverse factor

\section{Background}

The relationship between high-density lipoprotein cholesterol (HDL-C) levels and cardiovascular deaths has been demonstrated to be a U-shaped curve [1]. Such a relationship indicates that both extremely low and extremely high levels of HDL-C are potentially harmful. Low HDL-C was associated with higher mortalities

\footnotetext{
* Correspondence: sunlf02@outlook.com

Department of Cardiology, The First Hospital of China Medical University, 155 North Nanjing Street, 110001 Shenyang, Liaoning Province, China
}

compared with high HDL-C [2]. Thus, the cardiovascular mortality of those with extremely low HDL-C is highest. It is necessary to investigate the underlying mechanisms associated with extremely low levels of HDL-C. Although the prevalence of low HDL-C levels has been reported to be very high in different countries and regions [3-5], extremely low HDL-C levels, which are defined as $\mathrm{HDL}-\mathrm{C}<20 \mathrm{mg} / \mathrm{dL}(0.52 \mathrm{mmol} / \mathrm{L})$, were definitely rare [6].

C C The Author(s). 2021 Open Access This article is licensed under a Creative Commons Attribution 4.0 International License, which permits use, sharing, adaptation, distribution and reproduction in any medium or format, as long as you give appropriate credit to the original author(s) and the source, provide a link to the Creative Commons licence, and indicate if changes were made. The images or other third party material in this article are included in the article's Creative Commons licence, unless indicated otherwise in a credit line to the material. If material is not included in the article's Creative Commons licence and your intended use is not permitted by statutory regulation or exceeds the permitted use, you will need to obtain permission directly from the copyright holder. To view a copy of this licence, visit http://creativecommons.org/licenses/by/4.0/ The Creative Commons Public Domain Dedication waiver (http://creativecommons.org/publicdomain/zero/1.0/) applies to the data made available in this article, unless otherwise stated in a credit line to the data. 
Mutations of ATP-binding cassette transporter A1, lecithin: cholesterol acyltransferase or apolipoprotein AI, are known genetic causes of extremely low or even undetectable levels of HDL-C [7]. They are rare inherited disorders leading to defects in HDL formation or maturation. In the general population, acquired factors account for approximately half of the incidences of extremely low HDL-C [6]. Severe hypertriglyceridemia, especially when serum triglycerides are over $500 \mathrm{mg} / \mathrm{dL}$, may lead to very low HDL-C [8]. Marked reduction of HDL-C was described previously in patients with cholestatic liver disease, which suppressed elements of HDL assembly and maturation [6]. Specific medications, such as androgenic anabolic steroids and peroxisome proliferation activated receptor (PPAR) agonists, including thiazolidinedione and fibrates, were also found to cause extremely low levels of HDL-C [9]. Some lymphoproliferative diseases have been shown to sharply decrease HDL-C levels because of the simultaneous elevation in paraprotein or cytokine levels $[6,10]$. The factors listed above were related to severe HDL-C deficiency. In addition, diabetes, obesity and smoking are some common factors leading to mild and moderate decreases in HDL-C $[3,4,11,12]$.

Notably, individuals with genetic defects that lead to extremely low HDL-C levels are not always susceptible to cardiovascular diseases [13]. Large-scale Mendelian randomization studies proved that gene mutations attributed to changes in HDL-C concentration were not related to coronary atherosclerotic disease $[14,15]$. It is suspected that the high mortality of extremely low HDL$\mathrm{C}$ should be determined by phenotypes or other relevant concomitant factors. To date, little is known about the clinical characteristics that are exclusive to cardiovascular patients with extremely low HDL-C. Therefore, this research aims to study the relevant concomitant factors of cardiovascular patients with extremely low HDL-C levels in a single cardiology center.

\section{Methods}

\section{Study population}

Cardiovascular patients were retrospectively recruited from the Department of Cardiology at the First Hospital of China Medical University. To avoid differential effects caused by the season in which the cardiovascular patients were admitted, patients from January to December 2019 were chosen. Both outpatients and inpatients were included. Repeated HDL-C tests of the same subjects were excluded, except the first test. Patients under the age of 18 years were also excluded. Personal information, including sex, age, diagnosis and HDL-C level, was recorded for each subject.

Because detailed information could not be acquired from outpatients, only inpatients were further evaluated.
For inpatients with $\mathrm{HDL}-\mathrm{C}<20 \mathrm{mg} / \mathrm{dL}$, the levels for total cholesterol (TC), low-density lipoprotein cholesterol (LDL-C), triglyceride (TG), serum albumin, uric acid, estimated glomerular filtration rate (eGFR), hemoglobin, high-sensitivity C-reactive protein (hsCRP), free thyroxine (FT4), free triiodothyronine (FT3), thyroid stimulating hormone (TSH), glycosylated hemoglobin (HbA1C), as well as body mass index (BMI) on admission were also reviewed from hospitalization records. Medical history, specific diseases (cholestatic liver disease, acute hepatitis and HIV infection) and ongoing medications (androgenic steroids, thiazolidinediones and fibrates) were checked. They were paired with matched inpatients with normal levels of HDL-C $(40-60 \mathrm{mg} / \mathrm{dL})$ by sex, age and chief diagnosis from the same database. These matched patients with normal levels of HDL-C were set as the control group. The study was approved by the ethics committee of the hospital in accordance with the Declaration of Helsinki. Because this was a retrospective observational study without any interventional procedure on patients, written informed consent of the investigated subjects was exempted (Approved No. 2020307).

\section{HDL-C measures}

All blood samples were centrally tested in the clinical laboratory of the hospital. HDL-C levels were determined by a direct assay (Kyowa Medex, Japan) on a COBAS 8000 automatic biochemical analyzer (Roche, Germany). Because lipid profiles were reported in $\mathrm{mmol} / \mathrm{L}$, they were converted to $\mathrm{mg} / \mathrm{dL}$ to adhere to international guidelines by calculation (for triglycerides, $1 \mathrm{mmol} / \mathrm{L}=88.57 \mathrm{mg} / \mathrm{dL}$, and for cholesterol, $1 \mathrm{mmol} / \mathrm{L}=38.67 \mathrm{mg} / \mathrm{dL}$ ).

\section{Evaluations of relevant concomitant factors}

Several relevant conditions were selected as concomitant factors of extremely low levels of HDL-C, including hypercholesterolemia, hypertriglyceridemia, systemic inflammation, hypoalbuminemia, hyperuricemia, renal dysfunction, anemia, low T3 syndrome, obesity, diabetes, current smoking status, alcohol consumption and critical conditions. The definitions of these factors are presented in Table 1. Factors that were demonstrated to increase the possibility of extremely low levels of HDL-C were considered final adverse factors. Each adverse factor was given a score of 1 . Because the levels of TG and hsCRP both followed a skewed distribution, an additional score would be given respectively when hsCRP $\geq 10.0 \mathrm{mg} / \mathrm{L}$ and $\mathrm{TG} \geq$ $200 \mathrm{mg} / \mathrm{dL}$. The total risk score was calculated as the sum result of all the adverse factors for each individual.

\section{Statistical analysis}

Data analysis was performed with SPSS 23.0 software. Categorical data were expressed as case numbers and percentages. Continuous data were expressed as median 
Table 1 Definitions of relevant concomitant factors with extremely low HDL-C

\begin{tabular}{ll}
\hline Concomitant factors & Definition \\
\hline Hypercholesterolemia & $\mathrm{TC} \geq 200 \mathrm{mg} / \mathrm{dL}$ and/or $\mathrm{LDL}-\mathrm{C} \geq 130 \mathrm{mg} / \mathrm{dL}$ \\
Hypertriglyceridemia & $\mathrm{TG} \geq 150 \mathrm{mg} / \mathrm{dL}$ \\
Systemic inflammation & $\mathrm{hsCRP}>3.0 \mathrm{mg} / \mathrm{L}$ \\
Hypoalbuminemia & Serum albumin $<35 \mathrm{~g} / \mathrm{L}$ \\
Hyperuricemia & Uric acid $\geq 417 \mathrm{umol} / \mathrm{L}$ for male or uric \\
& acid $\geq 357 \mathrm{umol} / \mathrm{L}$ for female \\
Renal dysfunction & eGFR $<60 \mathrm{ml} / \mathrm{min} / 1.73 \mathrm{~m}^{2}$ \\
Anemia & Hemoglobin $<120 \mathrm{~g} / \mathrm{L}$ for male or \\
& hemoglobin $<110 \mathrm{~g} / \mathrm{L}$ for female \\
Low T3 syndrome & FT3 $<2.63 \mathrm{pmol} / \mathrm{L}$ with normal FT4 \\
and TSH & BMl $\geq 28 \mathrm{~kg} / \mathrm{m}^{2}$ \\
Diabetes & Prior history or HbA1C $\geq 6.5 \%$ \\
Current smoking & Smoking within 3 recent months \\
Alcohol consumption & Daily drinking of alcohol \\
Critical condition & MODS
\end{tabular}

HDL-C high-density lipoprotein cholesterol; TC total cholesterol; LDL-C lowdensity lipoprotein cholesterol; TG triglyceride; $h S C R P$ high-sensitive $C$-reactive protein; eGFR estimated glomerular filtration rate; T3 triiodothyronine; FT3 free triiodothyronine; FT4 free thyroxine; TSH thyroid stimulating hormone; BMI body mass index; $H b A 1 C$ glycosylated hemoglobin; MODS multiple organ dysfunction syndrome

(minimum, maximum) for skewed distribution or the mean \pm standard deviation for normal distribution. A trend test was performed to examine the linear trend between HDL-C level and age. Differences between groups of the extremely low HDL-C and the controls were compared by Student's t-test or nonparametric u-test for continuous variables. Univariate correlations between HDL-C levels and different parameters were evaluated by Pearson analysis or Spearman analysis. Multivariate linear regressions were performed to determine independent factors. To examine odds ratios (ORs) of the concomitant factors for those with extremely low HDL-
$C$ levels, logistic regression analysis was conducted. $P<$ 0.05 was set as a significant standard in statistics.

\section{Results}

\section{General clinical characteristics of participants}

The final analysis was composed of 8255 inpatients and 12,400 outpatients, with a total of 20,655 individuals. There were 10,775 males $(52.17 \%)$ and 9880 females $(47.83 \%)$. Their average age was $58.20 \pm 12.98$ years. The HDL-C level ranged from $3.9 \mathrm{mg} / \mathrm{dL}$ to $179.4 \mathrm{mg} /$ $\mathrm{dL}$. The mean HDL-C level was $46.0 \pm 13.5 \mathrm{mg} / \mathrm{dL}$. The HDL-C level of inpatients was much lower than that of outpatients $(40.6 \pm 11.6 \mathrm{mg} / \mathrm{dL}$ vs. $49.5 \pm 13.5 \mathrm{mg} / \mathrm{dL}, P<$ $0.001)$. Besides, the HDL-C levels of males were lower than levels of females $(41.8 \pm 12.0 \mathrm{mg} / \mathrm{dL}$ vs. $50.7 \pm$ $13.9 \mathrm{mg} / \mathrm{dL}, P<0.001)$. Levels of HDL-C presented an ascending trend with aging in male outpatients, female outpatients and male inpatients. Levels of HDL-C presented a descending trend with aging in female inpatients (Table 2).

Characteristics of patients with extremely low levels of HDL-C The percentages of patients with HDL-C levels under $40 \mathrm{mg} / \mathrm{dL}, 20 \mathrm{mg} / \mathrm{dL}$ and $15 \mathrm{mg} / \mathrm{dL}$ were $36.83 \%(n=$ $7607), 0.47 \%(n=98)$ and $0.17 \%(n=36)$, respectively. The average age of patients with HDL-C $<20 \mathrm{mg} / \mathrm{dL}$ was $60.7 \pm 15.1$ years. Among the 98 patients with HDL-C< $20 \mathrm{mg} / \mathrm{dL}$, there were 87 inpatients $(88.8 \%)$ and 76 were male $(77.6 \%)$.

The percentage of inpatients with HDL-C levels under $20 \mathrm{mg} / \mathrm{dL}$ was $1.05 \%$. For inpatients, the main causes of hospitalization were acute coronary syndrome $(n=50$, $57.5 \%)$, congestive heart failure $(n=21,24.1 \%)$ and acute myocarditis $(n=7,8.0 \%)$. There was no detected lymphoproliferative disease or use of androgenic anabolic steroids. A patient with cholestatic liver disease, a patient with fenofibrate medication and a third patient with triglycerides over $500 \mathrm{mg} / \mathrm{dL}$ were excluded from

Table 2 Linear trends of HDL-C levels with aging(mean \pm standard deviation, $\mathrm{mg} / \mathrm{dL}$ )

\begin{tabular}{|c|c|c|c|c|c|c|c|}
\hline Age (years) & $<40$ & $40-49$ & $50-59$ & $60-69$ & $70-79$ & $\geq 80$ & $P$ for trend \\
\hline \multicolumn{8}{|l|}{ Outpatients } \\
\hline Male & $42.2 \pm 10.4$ & $43.3 \pm 11.2$ & $45.2 \pm 12.0$ & $46.4 \pm 12.4$ & $48.0 \pm 13.1$ & $49.1 \pm 13.5$ & $<0.001$ \\
\hline Number of cases & 995 & 1064 & 1650 & 1632 & 521 & 151 & \\
\hline Female & $53.0 \pm 13.5$ & $53.0 \pm 13.5$ & $53.4 \pm 13.5$ & $53.4 \pm 13.1$ & $54.9 \pm 14.7$ & $55.7 \pm 15.1$ & $<0.001$ \\
\hline Number of cases & 500 & 902 & 1971 & 2055 & 761 & 198 & \\
\hline \multicolumn{8}{|l|}{ Inpatients } \\
\hline Male & $35.6 \pm 10.1$ & $35.6 \pm 8.9$ & $37.1 \pm 10.1$ & $38.3 \pm 10.1$ & $39.1 \pm 11.2$ & $39.1 \pm 12.4$ & $<0.001$ \\
\hline Number of cases & 335 & 550 & 1254 & 1715 & 678 & 230 & \\
\hline Female & $46.8 \pm 13.1$ & $46.8 \pm 13.9$ & $45.6 \pm 11.6$ & $44.9 \pm 11.6$ & $44.1 \pm 12.0$ & $44.5 \pm 12.8$ & 0.004 \\
\hline Number of cases & 142 & 201 & 775 & 1340 & 777 & 258 & \\
\hline
\end{tabular}

HDL-C high-density lipoprotein cholesterol 
comparison and scoring, in case these conditions made analysis confusing.

In the remaining 84 inpatients, the percentage of each relevant concomitant factor is presented in Fig. 1. The top three factors observed in inpatients with HDL-C $<$ $20 \mathrm{mg} / \mathrm{dL}$ were systemic inflammation (75.0\%), hyperuricemia (53.6\%) and hypoalbuminemia (47.6\%). For inpatients with $\mathrm{HDL}-\mathrm{C}<15 \mathrm{mg} / \mathrm{dL}$, the top three factors were systemic inflammation $(80.0 \%)$, hypoalbuminemia $(66.7 \%)$ and hyperuricemia $(63.3 \%)$. However, the top three factors for inpatients with HDL-C levels of 15$20 \mathrm{mg} / \mathrm{dL}$ were systemic inflammation (72.2\%), hyperuricemia $(48.1 \%)$ and smoking $(44.4 \%)$. In the univariate analysis, HDL-C levels were negatively correlated with hsCRP levels and positively correlated with LDL-C, serum albumin and FT3 levels. Parameters, such as age, TG, uric acid, eGFR, hemoglobin, BMI and HbA1C, did not correlate with HDL-C levels. The levels of LDL-C and FT3 were independent factors associated with HDL$\mathrm{C}$ levels according to multivariate regression (Table 3).

Differences between inpatients with extremely low HDL-C levels and their counterparts with normal HDL-C levels Inpatients with extremely low levels of HDL-C also exhibited lower levels of cholesterol, serum albumin, hemoglobin and FT3, compared with their counterparts with normal HDL-C. Conversely, they exhibited higher TG, hsCRP, uric acid, FT4, and HbA1C levels and a higher BMI. There was no difference in eGFR or TSH levels (Table 4). Systemic inflammation, hyperuricemia and hypoalbuminemia significantly increased the possibility of extremely low HDL-C levels to over five-fold of that of normal HDL-C levels. In addition, low T3 syndrome, anemia, diabetes and hypertriglyceridemia were also revealed to increase the likelihood of extremely low HDL-C. Hypercholesterolemia and alcohol consumption reduced the possibility of extremely low HDL-C (Table 5).

\section{Correlations between risk scores and HDL-C levels}

The final adverse factors were systemic inflammation, hyperuricemia, hypoalbuminemia, low T3 syndrome, anemia, diabetes and hypertriglyceridemia, as shown in Table 5. All except four patients had at least one adverse factor. There were 66 patients $(78.6 \%)$ who scored $\geq 3$ points, including $25(83.3 \%)$ in the HDL-C $<15 \mathrm{mg} / \mathrm{dL}$ subgroup, and $41(75.9 \%)$ in the HDL-C $15-20 \mathrm{mg} / \mathrm{dL}$ subgroup. The HDL-C levels negatively correlated with the total risk scores in patients whose HDL-C levels were below $20 \mathrm{mg} / \mathrm{dL}(r=-0.381, P<0.001)$ (Fig. $2 \mathrm{~A})$. In particular, the correlation became more significant in patients whose HDL-C levels were below $15 \mathrm{mg} / \mathrm{dL}$ ( $r=-$ 0.511, $P=0.004$ ) (Fig. 2B).

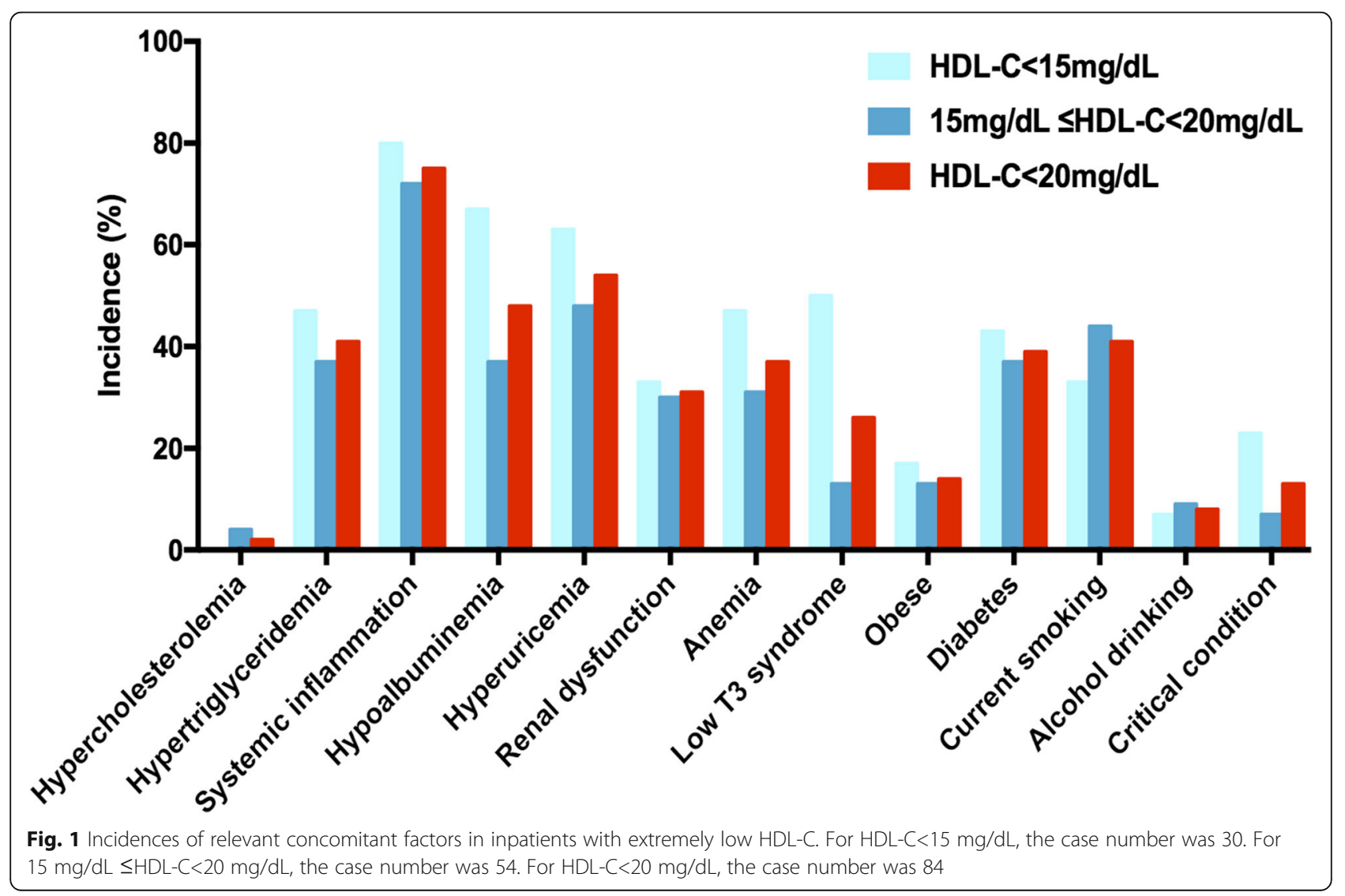


Table 3 Linear correlations and regressions between clinical parameters and HDL-C level in inpatients with extremely low HDL-C $(N=84)$

\begin{tabular}{|c|c|c|c|c|}
\hline & \multicolumn{2}{|c|}{ Univariate Correlation } & \multicolumn{2}{|c|}{ Multivariate Regression } \\
\hline & $r$ & $P$ & $\beta$ & $P$ \\
\hline Age(years) & -0.022 & 0.843 & 0.292 & 0.093 \\
\hline $\mathrm{LDL}-\mathrm{C}(\mathrm{mg} / \mathrm{dL})$ & 0.383 & $<0.001$ & 0.818 & 0.009 \\
\hline $\mathrm{TC}(\mathrm{mg} / \mathrm{dL})$ & 0.185 & 0.092 & -0.617 & 0.036 \\
\hline $\mathrm{TG}(\mathrm{mg} / \mathrm{dL})$ & -0.090 & 0.416 & -0.030 & 0.854 \\
\hline $\mathrm{hsCRP}(\mathrm{mg} / \mathrm{L})$ & -0.296 & 0.007 & 0.097 & 0.518 \\
\hline Serum albumin(g/L) & 0.369 & $<0.001$ & 0.152 & 0.332 \\
\hline Uric acid(umol/L) & -0.015 & 0.897 & -0.048 & 0.723 \\
\hline eGFR(ml/min/1.73m $\left.{ }^{2}\right)$ & -0.061 & 0.620 & -0.070 & 0.741 \\
\hline Hemoglobin(g/L) & 0.205 & 0.063 & 0.053 & 0.640 \\
\hline FT4(pmol/L) & 0.182 & 0.097 & 0.042 & 0.717 \\
\hline FT3(pmol/L) & 0.460 & $<0.001$ & 0.462 & 0.011 \\
\hline $\mathrm{TSH}(\mathrm{mIU} / \mathrm{L})$ & -0.090 & 0.416 & -0.114 & 0.278 \\
\hline $\mathrm{BMI}\left(\mathrm{kg} / \mathrm{m}^{2}\right)$ & -0.169 & 0.179 & -0.122 & 0.377 \\
\hline $\mathrm{HbA1C}(\%)$ & -0.088 & 0.436 & 0.039 & 0.715 \\
\hline
\end{tabular}

HDL-C high-density lipoprotein cholesterol; $T C$ total cholesterol; $L D L-C$ low-density lipoprotein cholesterol; TG triglyceride; $h s C R P$ high-sensitive $C$-reactive protein; eGFR estimated glomerular filtration rate; FT4 free thyroxine; FT3 free triiodothyronine; TSH thyroid stimulating hormone; BMI body mass index; HbA1C glycosylated hemoglobin. $r$ represented coefficient of univariate correlation between $\mathrm{HDL}-\mathrm{C}$ levels and parameters. $\beta$ represented standard coefficient of multivariate regression between $\mathrm{HDL}-\mathrm{C}$ levels and parameters

\section{Discussion}

This observational study, for the first time, demonstrated several clinical characteristics of cardiovascular patients with extremely low levels of HDL-C. (1) These patients were likely to be males and inpatients. Although there was an ascending trend of HDL-C with aging in general, the relatively old age of these individuals implies that they might be more severely ill than the other individuals. (2) The common concomitant factors of extremely low levels of HDL-C were systemic inflammation, hyperuricemia, hypoalbuminemia and low T3 syndrome. These factors were essentially different from the common factors that were associated with mildly and moderately low HDL-C levels, which were

Table 4 Comparisons between inpatients with extremely low HDL-C and normal HDL-C

\begin{tabular}{llll}
\hline & Low Group $(\mathbf{N = 8 4 )}$ & Normal Group $(\mathbf{N = 8 4 )}$ & $P$ \\
\hline HDL-C(mg/dL) & $15.9 \pm 4.1$ & $48.8 \pm 5.4$ & $<0.001$ \\
LDL-C(mg/dL) & $72.6 \pm 28.6$ & $104.5 \pm 35.6$ & $<0.001$ \\
TC(mg/dL) & $118.6 \pm 30.7$ & $170.4 \pm 40.3$ & $<0.001$ \\
TG(mg/dL) & $125.3(46.1,435.8)$ & $93.9(19.5,265.7)$ & $<0.001$ \\
hsCRP(mg/L) & $15.60(0.15,402)$ & $1.89(0.15,190)$ & $<0.001$ \\
Serum albumin(g/L) & $35.2 \pm 6.4$ & $39.3 \pm 5.2$ & $<0.001$ \\
Uric acid(umol/L) & $454 \pm 186$ & $328 \pm 99$ & $<0.001$ \\
eGFR(ml/min/1.73m $\left.{ }^{2}\right)$ & $84.35 \pm 39.48$ & $88.45 \pm 38.26$ & 0.521 \\
Hemoglobin(g/L) & $125 \pm 24$ & $136 \pm 21$ & 0.003 \\
FT4(pmol/L) & $13.80 \pm 2.52$ & $12.98 \pm 1.73$ & 0.015 \\
FT3(pmol/L) & $3.17 \pm 0.83$ & $3.93 \pm 0.75$ & $<0.001$ \\
TSH(mlU/L) & $1.63 \pm 1.39$ & $1.92 \pm 1.28$ & 0.163 \\
BMI(kg/ m $\left.{ }^{2}\right)$ & $25.22 \pm 3.97$ & $23.78 \pm 3.47$ & 0.024 \\
HbA1C(\%) & $6.8 \pm 1.4$ & $6.0 \pm 0.9$ & $<0.001$ \\
\hline
\end{tabular}

HDL-C high-density lipoprotein cholesterol; TC total cholesterol; $L D L-C$ low-density lipoprotein cholesterol; $T G$ triglyceride; $h s C R P$ high-sensitive $C$-reactive protein; eGFR estimated glomerular filtration rate; FT4 free thyroxine; FT3 free triiodothyronine; TSH thyroid stimulating hormone; BMI body mass index; HbA1C glycosylated hemoglobin. Data were expressed as mean \pm standard deviation for normal distribution or median (minimum, maximum) for skewed distribution 
Table 5 Logistic regressions of relevant concomitant factors for inpatients with extremely low HDL-C

\begin{tabular}{|c|c|c|}
\hline & OR $(95 \% \mathrm{Cl})$ & $P$ \\
\hline Hypercholesterolemia & $0.065(0.015-0.285)$ & $<0.001$ \\
\hline Hypertriglyceridemia & $2.493(1.264-4.918)$ & 0.008 \\
\hline Systemic inflammation & $5.556(2.798-11.030)$ & $<0.001$ \\
\hline Hypoalbuminemia & $5.714(2.702-12.085)$ & $<0.001$ \\
\hline Hyperuricemia & $5.156(2.560-10.386)$ & $<0.001$ \\
\hline Renal dysfunction & $1.589(0.763-3.308)$ & 0.216 \\
\hline Anemia & $3.577(1.680-7.617)$ & $<0.001$ \\
\hline Low T3 syndrome & $4.278(1.627-11.245)$ & 0.003 \\
\hline Obese & $1.833(0.684-4.914)$ & 0.228 \\
\hline Diabetes & $3.534(1.693-7.376)$ & 0.001 \\
\hline Current smoking & $1.916(0.997-3.682)$ & 0.051 \\
\hline Alcohol consumption & $0.386(0.150-0.995)$ & 0.049 \\
\hline Critical condition & $2.381(0.789-7.181)$ & 0.124 \\
\hline
\end{tabular}

hypercholesterolemia, smoking or obesity. (3) Extremely low HDL-C levels tended to be a comprehensive result of multiple adverse concomitant factors in cardiovascular patients. The HDL-C level might be reduced with severity and an increasing number of adverse concomitant factors.

\section{Comparisons with other studies and contributions of the current study}

Sex-specific differences have been reported in both clinical manifestations and treatment outcomes [16]. The fact that extremely low HDL-C levels were more prevalent in males than females indicates the importance of exploring sex-specific approaches to the evaluation and treatment of HDL-C in the future. Low T3 syndrome is the state of decreased triiodothyronine with normal thyroxine and $\mathrm{TSH}$, and it is an indicator of severe illnesses [17]. In this study, low T3 syndrome was found in half of the HDL-C $<15 \mathrm{mg} / \mathrm{dL}$ cases, but it was not common in the HDL-C $15-20 \mathrm{mg} / \mathrm{dL}$ subgroup. This meant that the patients in HDL-C $15-20 \mathrm{mg} / \mathrm{dL}$ subgroup were in relatively better condition and might show factors that are similar to that of patients with moderate HDL-C levels, such as smoking, obesity and other common factors.

A high level of uric acid indicates an imbalance in purine metabolism with more production and less excretion. In patients with extremely low HDL-C levels, comparatively severe conditions might be a factor leading to fast catabolism and reduced renal function. Therefore, net accumulation of uric acid in circulation results in a high prevalence of hyperuricemia. Surprisingly, there was no significant reduction in renal function in this study.
Therefore, hyperuricemia should be an independent factor associated with extremely low levels of HDL-C. A negative correlation of HDL-C and uric acid levels has been reported in previous studies $[18,19]$. In contrast to metabolic syndrome, hyperuricemia was not parallel with obesity, hypertriglyceridemia or diabetes in those with extremely low HDL-C. Both hypoalbuminemia and anemia are signs of poor nutrition status. A crosssectional study demonstrated that serum albumin $\leq 35 \mathrm{~g} /$ $\mathrm{L}$ independently predicted HDL-C $<30 \mathrm{mg} / \mathrm{dL}$ in patients with acute coronary syndrome [20]. Although albumin might act as a potent cholesterol carrier and opponent of apolipoproteins [21, 22], a simultaneous lack of the main protein element of HDL, namely, apoA-I, might occur when albumin levels decrease. A similar explanation could involve low total cholesterol levels, which is supported by a positive association between albumin and total cholesterol levels in the US population [23].

It was reported that critical illnesses, such as severe sepsis, induced a decrease in HDL cholesterol content [24]. However, infection was not the only cause. Only a few inpatients in the current investigation had an acute infection. The systemic inflammation indicator hsCRP was notably elevated in the majority of patients to different extents. Forty-seven of the 84 patients in this study had severe systemic inflammation (hsCRP $>10.0 \mathrm{mg} / \mathrm{L}$ ). This implies a close relationship between inflammation and decreased HDL-C levels, probably in a dosedependent manner. Even under lipid-lowering therapy, HDL-C and hsCRP levels maintained an inverse relationship [25]. There are two possible reasons. One reason is that the cholesterol efflux ability of HDL might be attenuated in an inflammatory cardiovascular background, resulting in a decrease in cholesterol content on HDL [26, 27]. The second reason is that, as the team of Alan reported, anti-inflammatory cytokines induced endocytosis of HDL and LDL into macrophages, leading to temporarily low HDL and LDL cholesterol levels in serum [28].

HDL-C level has been challenged time and time again for its association with cardiovascular diseases. Instead, the HDL function may be the real link with cardiovascular diseases [29]. Since the role of HDL in prevention and progression of cardiovascular diseases remains to be further clarified, we assume, in the current study, that extremely low level of HDL-C is only a marker, which reflects a comprehensive result of multiple adverse concomitant factors, and the high cardiovascular mortality is probably due to the presence of severe conditions. Previously, Mohsen and colleagues found that inflammation was an important factor associated with extremely low HDL-C levels [30]. HDL also exerts antiinflammatory properties [31]. Furthermore, inflammation might be involved in hyperuricemia and hypoalbuminemia 




B

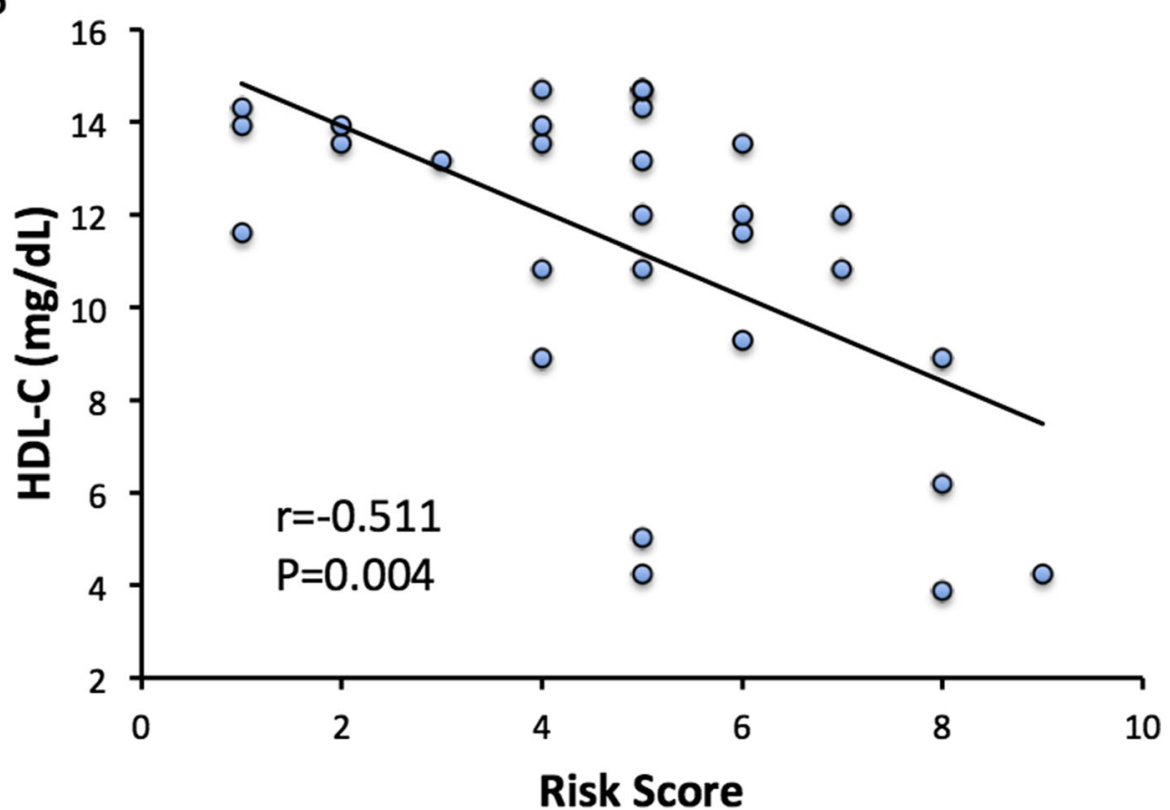

Fig. 2 Reverse correlations between risk scores and HDL-C levels in inpatients with extremely low HDL-C. A Correlation between risk score and $\mathrm{HDL}-\mathrm{C}$ level in inpatients with $\mathrm{HDL}-\mathrm{C}<20 \mathrm{mg} / \mathrm{dL}(\mathrm{N}=84)$. B Correlation between risk score and $\mathrm{HDL}-\mathrm{C}$ level in inpatients with $\mathrm{HDL}-\mathrm{C}<15 \mathrm{mg} / \mathrm{dL}(\mathrm{N}=30)$

[32-34], and reduced HDL-C was repeatedly reported in inflammatory states, such as smoking, diabetes, obesity and even the recent COVID-19 [35, 36]. Thus, systemic inflammation, the most prevalent factor in this study, may be the core of all the adverse factors associated with the alterations of HDL cholesterol content. Our previous study demonstrated that the HDL-C/hsCRP ratio was superior to hSCRP in relation to left ventricular diastolic dysfunction [37], which was considered an inflammationmediated abnormality [38]. Perhaps HDL-C should be considered a comprehensive inflammatory marker rather than a simple lipid value. Meanwhile, we could not deny the potential interrelationship among the concomitant factors being chosen in the study. Although as far as we can imagine, they are common clinical conditions that may be associated with HDL-C reduction, it is inevitable that these concomitant factors could be related with each other, as inflammation involves the link between cholesterol level and cardiovascular diseases [39]. Therefore, multivariate regressions between clinical parameters and HDL-C level were checked. The inflammatory parameter, which negatively correlated with HDL-C in univariate 
correlation, was not an independent parameter associated with HDL-C. This, in turn, implies that inflammation relates with other factors.

\section{Study strength and limitations}

This study exclusively investigated cardiovascular patients with extremely low HDL-C levels for the first time and provides possible explanations for the high cardiovascular mortality of such unique individuals. However, several limitations should be noted.

Because this is a retrospective observational study conducted in a single center, the representativeness and persuasiveness of the results were limited. Thus, a causal relationship for each factor could not be established. In addition, the HDL-C levels of these patients at baseline and after treatment were not compared. In this case, the effect strengths of the adverse concomitant factors in this study were not definitely clear. Lipoprotein(a), the newly known lipid parameter associated with cardiovascular events [40], was not investigated. Thus, some useful information might be missing accordingly. Besides those specific medicines, which can induce sharp HDL$\mathrm{C}$ reduction, lipid-modifying drugs, such as statins, may more or less impact the level of HDL-C and cardiovascular outcomes. Although we excluded cases with ongoing use of the specific medicines during the process of statistical analysis, we did not stratify cases according to other detailed lipid-modifying medications because of the small sample size. As a result, we could not conclude whether the results were attributed to cholesterol levels or effects of drugs, just like the concerns of Cholesterol Treatment Trialists' Collaborators [41]. A similar investigation reported the clinical features of general patients with extremely low levels of HDL-C. It demonstrated that the proportion of cardiovascular diseases in these patients was much lower than that of malignancies [42]. This explains why the prevalence of extremely low HDL-C in the current study was lower than expected. Although over 20,000 patients were investigated, less than one hundred patients met the criteria. As a result, the size of samples was comparatively small. This study only serves as a pilot study, and the results still require further validation. According to the same study, nearly $99 \%$ of patients had secondary causes, which is much higher than the proportion in the general population [42]. Although genetic causes were not identified, especially in the four individuals without any adverse concomitant factors, this study could still represent a majority of cases.

\section{Conclusions}

The clinical characteristics of cardiovascular patients with extremely low levels of HDL-C are different from those commonly seen in individuals with mild and moderate HDL-C decrease. Extremely low levels of HDL-C tend to occur more frequently in males, relatively old individuals and inpatients. These low levels are usually due to the presence of multiple adverse factors with relatively severe conditions in cardiovascular patients. This could explain the high cardiovascular mortality rate of individuals with extremely low HDL-C levels. In the future, attention and special cares should be given to such patients to reduce mortality.

\section{Abbreviations \\ BMI: body mass index; eGFR: estimated glomerular filtration rate; FT3: free triiodothyronine; FT4: free thyroxine; HbA1C: glycosylated hemoglobin; HDL- C: high-density lipoprotein cholesterol; hsCRP: high-sensitive C-reactive pro- tein; LDL-C: low-density lipoprotein cholesterol; PPAR: peroxisome proliferation activated receptor; TC: total cholesterol; TG: triglyceride; TSH: thyroid stimulating hormone}

\section{Acknowledgements}

We thank the clinical staff in the cardiology center and clinical laboratory for their support and contribution to the project.

\section{Authors' contributions}

L.S. designed the study, collected data, analyzed data and drafted the original manuscript. L.D. collected data, analyzed data and drafted the original manuscript. D.J. designed the study, guided data interpretation and revised manuscript. All authors read and approved the final manuscript.

\section{Funding}

This study was supported by the National Natural Science Foundation of China (Grant No.81670320).

\section{Availability of data and materials}

All data generated and analysed during this study are included in this published article.

\section{Declarations}

\section{Ethics approval and consent to participate}

The study protocol was approved by the ethics committee of the First Hospital of China Medical University. Written informed consent was exempted from each participate.

\section{Consent for publication}

Not applicable.

\section{Competing interests}

The authors declare that they have no competing financial interests or personal relationships that could have appeared to influence the work reported in this paper.

Received: 17 August 2021 Accepted: 19 October 2021

Published online: 30 October 2021

\section{References}

1. Madsen CM, Varbo A, Nordestgaard BG. Extreme high high-density lipoprotein cholesterol is paradoxically associated with high mortality in men and women: two prospective cohort studies. Eur Heart J. 2017;38: 2478-86.

2. Kobayashi D, Noto H, Shimbo T, Ino T, Osugi Y, Takahashi O, et al. Repeated measures of extremely high levels of high-density lipoprotein cholesterol and subsequent all-cause mortality and cardiovascular events: A longitudinal study. Atherosclerosis. 2019;288:17-25.

3. Ge P, Dong C, Ren X, Weiderpass E, Zhang C, Fan H, et al. The High Prevalence of Low HDL-Cholesterol Levels and Dyslipidemia in Rural Populations in Northwestern China. PLoS One. 2015;10:e0144104.

4. Connelly PW, Petrasovits A, Stachenko S, MacLean DR, Little JA, Chockalingam A. Prevalence of high plasma triglyceride combined with low $\mathrm{HDL}-\mathrm{C}$ levels and its association with smoking, hypertension, obesity, 
diabetes, sedentariness and LDL-C levels in the Canadian population. Canadian Heart Health Surveys Research Group. Can J Cardiol. 1999;15: 428-33.

5. Kim SM, Han JH, Park HS. Prevalence of low HDL-cholesterol levels and associated factors among Koreans. Circ J. 2006;70:820-6.

6. Goldberg RB, Mendez AJ. Severe acquired (secondary) high-density lipoprotein deficiency. J Clin Lipidol. 2007;1:41-56.

7. Nair DR, Nair A, Jain A. HDL genetic defects. Curr Pharm Des. 2014;20: 6230-7.

8. Rader DJ, deGoma EM. Approach to the patient with extremely low HDLcholesterol. J Clin Endocrinol Metab. 2012;97:3399-407.

9. Goldberg RB, Rader D. The disappearing high density lipoprotein syndrome. J Clin Lipidol. 2015;9:91-2.

10. Moraitis AG, Freeman LA, Shamburek RD, Wesley R, Wilson W, Grant CM, et al. Elevated interleukin-10: a new cause of dyslipidemia leading to severe HDL deficiency. J Clin Lipidol. 2015;9:81-90.

11. Devroey D, De Swaef N, Coigniez P, Vandevoorde J, Kartounian J, Betz W. Correlations between lipid levels and age, gender, glycemia, obesity, diabetes, and smoking. Endocr Res. 2004;30:83-93.

12. Zhao X, Zhang HW, Zhang Y, Li S, Xu RX, Sun J, et al. Impact of Smoking Status on Lipoprotein Subfractions: Data from an Untreated Chinese Cohort. Biomed Environ Sci. 2017;30:235-43.

13. Sourlas A, Kosmas CE. Inheritance of high and low HDL: mechanisms and management. Curr Opin Lipidol. 2019;30:307-13.

14. Voight BF, Peloso GM, Orho-Melander M, Frikke-Schmidt R, Barbalic M Jensen MK, et al. Plasma HDL cholesterol and risk of myocardial infarction: a mendelian randomisation study. Lancet. 2012;380:572-80.

15. Prats-Uribe A, Sayols-Baixeras S, Fernandez-Sanles A, Subirana I, CarrerasTorres R, Vilahur G, et al. High-density lipoprotein characteristics and coronary artery disease: a Mendelian randomization study. Metabolism. 2020;112:154351.

16. Calabro P, Niccoli G, Gragnano F, Grove EL, Vergallo R, Mikhailidis DP, et al Are we ready for a gender-specific approach in interventional cardiology? Int J Cardiol. 2019;286:226-33.

17. Fliers E, Boelen A. An update on non-thyroidal illness syndrome. J Endocrinol Invest. 2021:44:1597-607.

18. Chen D, Zhang H, Gao Y, Lu Z, Yao Z, Jiang Y, et al. Cross-sectional and longitudinal associations between serum uric acid and metabolic syndrome: Results from Fangchenggang Area Male Health and Examination Survey in China. Clin Chim Acta. 2015:446:226-30.

19. Cibickova L, Langova K, Vaverkova H, Kubickova V, Karasek D. Correlation of uric acid levels and parameters of metabolic syndrome. Physiol Res. 2017;66: 481-7.

20. Gonzalez-Pacheco H, Amezcua-Guerra LM, Vazquez-Rangel A, MartinezSanchez C, Perez-Mendez O, Verdejo J, et al. Levels of High-Density Lipoprotein Cholesterol are Associated With Biomarkers of Inflammation in Patients With Acute Coronary Syndrome. Am J Cardiol. 2015;116:1651-7.

21. Meierhofer T, van den Elsen JMH, Cameron PJ, Munoz-Berbel X, Jenkins ATA. The Interaction of Serum Albumin with Cholesterol Containing Lipid Vesicles. J Fluoresc. 2010;20:371-6.

22. Zhao Y, Marcel YL. Serum albumin is a significant intermediate in cholesterol transfer between cells and lipoproteins. Biochemistry. 1996;35: 7174-80.

23. Gillum RF. The association between serum albumin and HDL and total cholesterol. J Natl Med Assoc. 1993:85:290-2.

24. Marik PE. Dyslipidemia in the critically ill. Crit Care Clin. 2006;22:151-9, viii.

25. Brown W, Foody JM, Zieve FJ, Tomassini JE, Shah A, Tershakovec AM. Inverse relationship between high-density lipoprotein cholesterol raising and high-sensitivity C-reactive protein reduction in older patients treated with lipid-lowering therapy. J Clin Lipidol. 2016;10:116-23.

26. Soares AAS, Tavoni TM, de Faria EC, Remalay AT, Maranhao RC, Sposito AC, et al. HDL acceptor capacities for cholesterol efflux from macrophages and lipid transfer are both acutely reduced after myocardial infarction. Clin Chim Acta. 2018:478:51-6.

27. Ebtehaj S, Gruppen EG, Bakker SJL, Dullaart RPF, Tietge UJF. HDL (HighDensity Lipoprotein) Cholesterol Efflux Capacity Is Associated With Incident Cardiovascular Disease in the General Population A Case-Control Study From the PREVEND Cohort. Arterioscl Throm Vas. 2019;39:1874-83.

28. Lucero D, Islam P, Freeman LA, Jin X, Pryor M, Tang J, et al. Interleukin 10 promotes macrophage uptake of $\mathrm{HDL}$ and $\mathrm{LDL}$ by stimulating fluid-phase endocytosis. Biochim Biophys Acta Mol Cell Biol Lipids. 2020;1865:158537.
29. Casula M, Colpani O, Xie S, Catapano AL, Baragetti A. HDL in Atherosclerotic Cardiovascular Disease: In Search of a Role. Cells. 2021:10:1869.

30. Mazidi M, Mikhailidis DP, Banach M. Associations between risk of overall mortality, cause-specific mortality and level of inflammatory factors with extremely low and high high-density lipoprotein cholesterol levels among American adults. Int J Cardiol. 2019;276:242-7.

31. Jomard A, Osto E. High Density Lipoproteins: Metabolism, Function, and Therapeutic Potential. Front Cardiovasc Med. 2020;7:39.

32. Vekic J, Jelic-Ivanovic Z, Spasojevic-Kalimanovska V, Memon L, Zeljkovic A, Bogavac-Stanojevic N, et al. High serum uric acid and low-grade inflammation are associated with smaller LDL and HDL particles. Atherosclerosis. 2009;203:236-42

33. Quispe EA, Li XM, Yi H. Comparison and relationship of thyroid hormones, IL-6, IL-10 and albumin as mortality predictors in case-mix critically ill patients. Cytokine. 2016;81:94-100.

34. Vavrova L, Rychlikova J, Mrackova M, Novakova O, Zak A, Novak F. Increased inflammatory markers with altered antioxidant status persist after clinical recovery from severe sepsis: a correlation with low HDL cholesterol and albumin. Clin Exp Med. 2016;16:557-69.

35. Piva SJ, Tatsch E, De Carvalho JAM, Bochi GV, Kober H, Duarte T, et al. Assessment of Inflammatory and Oxidative Biomarkers in Obesity and Their Associations with Body Mass Index. Inflammation. 2013;36:226-31.

36. Wang G, Zhang Q, Zhao X, Dong H, Wu C, Wu F, et al. Low high-density lipoprotein level is correlated with the severity of COVID-19 patients: an observational study. Lipids Health Dis. 2020;19:204.

37. Sun LF, Liu XR, Li WN, Jia DL. HDL-C to hsCRP ratio is associated with left ventricular diastolic function in absence of significant coronary atherosclerosis. Lipids in Health Disease. 2019;18:219.

38. Paulus WJ, Tschope C. A novel paradigm for heart failure with preserved ejection fraction: comorbidities drive myocardial dysfunction and remodeling through coronary microvascular endothelial inflammation. J Am Coll Cardiol. 2013;62:263-71.

39. Bernelot Moens SJ, Verweij SL, Schnitzler JG, Stiekema LCA, Bos M, Langsted A, et al. Remnant Cholesterol Elicits Arterial Wall Inflammation and a Multilevel Cellular Immune Response in Humans. Arterioscler Thromb Vasc Biol. 2017;37:969-75

40. Gragnano F, Fimiani F, Di Maio M, Cesaro A, Limongelli G, Cattano D, et al. Impact of lipoprotein(a) levels on recurrent cardiovascular events in patients with premature coronary artery disease. Intern Emerg Med. 2019;14:621-5.

41. Baigent C, Keech A, Kearney PM, Blackwell L, Buck G, Pollicino C, et al. Efficacy and safety of cholesterol-lowering treatment: prospective metaanalysis of data from 90,056 participants in 14 randomised trials of statins. Lancet. 2005;366:1267-78.

42. Tada H, Kawashiri MA, Konno T, Nohara A, Inazu A, Mabuchi H, et al. Prevalence, clinical features, and prognosis of patients with extremely low high-density lipoprotein cholesterol. J Clin Lipidol. 2016:10:1311-7.

\section{Publisher's Note}

Springer Nature remains neutral with regard to jurisdictional claims in published maps and institutional affiliations.

Ready to submit your research? Choose BMC and benefit from:

- fast, convenient online submission

- thorough peer review by experienced researchers in your field

- rapid publication on acceptance

- support for research data, including large and complex data types

- gold Open Access which fosters wider collaboration and increased citations

- maximum visibility for your research: over $100 \mathrm{M}$ website views per year

At $\mathrm{BMC}$, research is always in progress.

Learn more biomedcentral.com/submissions 